\title{
$7 \quad$ An academic lead in developing sustainable Arctic communities
}

\author{
Co-creation, quintuple helix, \\ and open social innovation
}

\author{
Martin Mohr Olsen
}

\section{Introduction}

In the pursuit of renewable economies and communities within the Arctic, it is essential that we keep in mind the regenerative properties and inherent potential for renewal contained within the region's institutions of higher learning. While colleges and universities in the periphery naturally tend to be smaller and less resourceful compared to their metropolitan counterparts - they are, more often than not, centers of specialised local and regional knowledge. Not only do institutions of higher learning located in remote regions often play a vital part in maintaining and developing local languages, practices, and cultures - they are also ideal incubators for the education and training of local agents of change capable of making a genuine impact on both local and regional issues. Realising that smaller institutions can often be protective and somewhat conservative, it is nevertheless of growing importance that they make an increased, systematic, and collaborative effort toward engagement in issues of sustainability on multiple operational levels in order to combat many issues facing the Arctic region; climate change and ecological challenges that affect the sustainability of communities, political, geopolitical, and securitisation issues, effects from resource extraction, impacts of increasing tourism, etc. (Arctic Council, 2016).

While it may be easy to tout the benefits and values of small, local, and specialised universities - it should also be acknowledged that universities in the periphery are fighting at least two distinct, yet interwoven, problems. On the one hand, Arctic universities often rely heavily or entirely on government subsidies that are often subject to prevailing political moods and often see allocations differ from year to year, making it hard to plan ahead and plan for long-term commitments or strategies. Located in smaller countries and communities, they are also often unable to attract major sources of external funding from benefactors or industry and establishment of largescale research projects is similarly rare. As issues of sustainability facing the Arctic mentioned align with all three aspects of sustainability; economic, environmental, and social - the involvement of universities as key stakeholders is paramount for the development of much-needed solutions. At the 
same time, unfortunately, such demands for solutions to often very complex issues can place an even greater burden upon the universities.

In this chapter, I will argue that smaller institutions of higher learning within the Arctic must play a greater role in tackling the issues facing the region in a more practical sense. They should work with geographically embedded knowledge in a real-work setting and focus on solutions relevant to the area and its stakeholders. However, I will also argue that for this to become a reality, changes to how many small Arctic universities currently operate must be made. What follows is an attempt to outline an operational framework that addresses the two problematics mentioned above; issues of resources and sustainability. The framework presented is an early attempt at a conceptual visualisation of all the different practical aspects that universities in the Arctic will need to consider systematically in order to minimise reliance on input resources in order to maximise their sustainability output. The framework is being developed for use by the new Innovation Unit at the University of the Faroe Islands and is under continual revision. In order to explain the basic framework, a point-by-point analysis of each step in the process will be given, outlining a theoretical basis and practical considerations.

\section{Background and context}

Before we get to the conceptual framework, there are two contextual aspects that should be clarified. First, some background on how this project is based on prior work and attempts to speak to some objective needs with Arctic academia, and secondly, a short description of the newly formed Innovation Unit at the University of the Faroe Islands, and their role in the project, will be given.

\section{Initial insights}

The chapter is an attempt to follow up on our recent review of emerging trends within the Arctic academic environment (for more, see, Blaxekjær et al., 2018). The first of these trends is a cross-sector demand for more innovative and entrepreneurial skills to be included in academic courses and curriculums. Where the main justification for entrepreneurship and innovation in an academic setting was initially economic growth-it can now be found in most academic fields (Chiu, 2012; Reffstrup \& Kærn Christiansen, 2017). Second, there is a growing interest in going beyond the three main pursuits that are at the core of most university mission statements (teaching, research, and dissemination). This fourth emerging mission statement, at times, referred to as "co-creation of sustainability" (Trencher et al., 2014) is in many cases a way for universities to experiment with novel triple- and quadruple helix models that can facilitate cooperation, but has also allowed them to diversify from purely economic pursuits to a wider 
array of non-commercial purposes dealing with sustainability (Trencher et al., 2014; Rosenlund, Rosell, \& Hogland, 2017). Third, the Sustainable Development Goals (SDGs) have also, however slowly, begun to take hold in the Arctic region. Places of higher learning, such as the University of the Faroe Islands, the University of Greenland, and local stakeholders in general, are noticing the benefits of taking a stance on including sustainability into their missions. In recent years, there has been a positive increase in the amount of focus given to the SDGs within Arctic universities. And, fourth, as is evidenced by the number of conferences and university collaborations with a focus on the Arctic and sustainability - there is a genuine window of opportunity for smaller regional universities to make their mark and take part in the growing interest in the region and the resources available. While we have seen an increasing interest in these trends over the last couple of years, it is important to note that for smaller Arctic universities, acting on and realising these interests can be a challenge. As has been mentioned above, a large number of Arctic universities are publicly funded, are lacking in resources and staff, are spread out over a vast geographic area where travel is expensive and cumbersome, and often lack networking possibilities and the patronage of large donors or collaborators.

\section{The innovation unit ${ }^{1}$}

Reacting to these emerging trends, the University of the Faroe Islands decided to initiate a response in the form of a small and lean project office that will be tasked with analysing and mapping best practices available to a relatively small and resource-weak institution. Novel to the University of the Faroe Islands, we were able to secure funding for a full-time member of staff that was not bound by any teaching responsibilities or office work. The Innovation Unit is headed by a coordinator not affiliated with any specific department or academic discipline, rather she answers to the rector and the board of directors. The unit is intended to be flexible and nimble in that it can incorporate members of staff for short-term projects as well as initiate long-term working groups for larger initiatives. As such, the name Innovation Unit was deliberately chosen in order to convey its ad hoc configuration and the non-physical placement within the conventional organisational hierarchy.

The main intent behind the Unit is to have it function as an auxiliary support on matters that would otherwise be beyond the scope of the duties of the university management staff and beyond the resources of the research staff. It is meant to facilitate and coordinate projects and initiatives that would previously likely have fallen into the boundary between two organisational camps, resulting in inaction. By adhering to the tenets of boundary spanning, the unit attempts to push a holistic agenda of maximising benefits on behalf of not only the university as a whole, but also the wider community it finds itself in (Tushman, 1977). It purposely looks to deal with 
complex projects that can be classified as "wicked issues," projects that cross academic disciplines and rely on the participation of multiple departments, civil society, municipalities, governmental agencies, and industry to solve (Williams, 2002).

The initial findings for the Innovation Unit reveal that there are four distinct, yet overlapping, foundational changes that should be made at an institutional level in order to meet these growing trends relating to sustainability. First, using the SDGs as primary guidelines in decision making and in the evaluation of the viability of new projects or existing modes of operation. Second, adding to the core mission statements of the organisation (teaching, researching, and knowledge transferal) to include a fourth mission statement of sustainable co-creation. Third, revising and formalising how the university deals with external stakeholders based on sound Helix models. Fourth, the implementation of modern innovation protocols such as Open Innovation and Social Innovation in order to foster local capacity building, dialogue, a shared sense of ownership, and mechanisms that can mitigate risk and help launch socially beneficial initiatives beyond the initial stages of prototyping and proof-of-concept.

\section{A framework for the future}

In an effort to outline the conceptual framework proposed for the Innovation Unit, what follows is an analysis of the constituent theoretical elements contained within it. First, I will argue for a systematic implementation of the Sustainable Development Goals. Secondly, I will give an historical summary of the university mission statement and then turn my attention to the arguments for a review of the beneficial addition of a fourth-mission statement based on sustainability co-creation as is outlined in Trencher et al. (2014). Third, I will give a quick overview of the Triple Helix approach and then focus in on Ranga and Etzkowitz (2013) analysis of Triple Helix Spaces, followed by a quick outline of the benefits and utility of quadruple- and quintuple-helix models as they are outlined in Carayannis and Campbell (2012) and Carayannis, Barth, and Campbell (2012). Fourth, I will provide some background relating to both Open and Social Innovation and then focus on how these two approaches could favorably be combined into the new concept of Open Social Innovation as has been outlined in Chesbrough and Di Minin (2014) and Martins and De Souza Bermejo (2014). I will then conclude that these four theoretical concepts (the SDGs, academic mission statements, Helix Models, and innovation frameworks), when combined into a framework, allow a small university such as the University of the Faroe Islands to put forward a set of guidelines that are both rigid in terms of adherence to sustainability and co-creation, while also being flexible in terms of scale and resources.

The conceptual operational framework, as seen in Figure 7.1, has been adapted and expanded upon based on the initial work done by Martins 


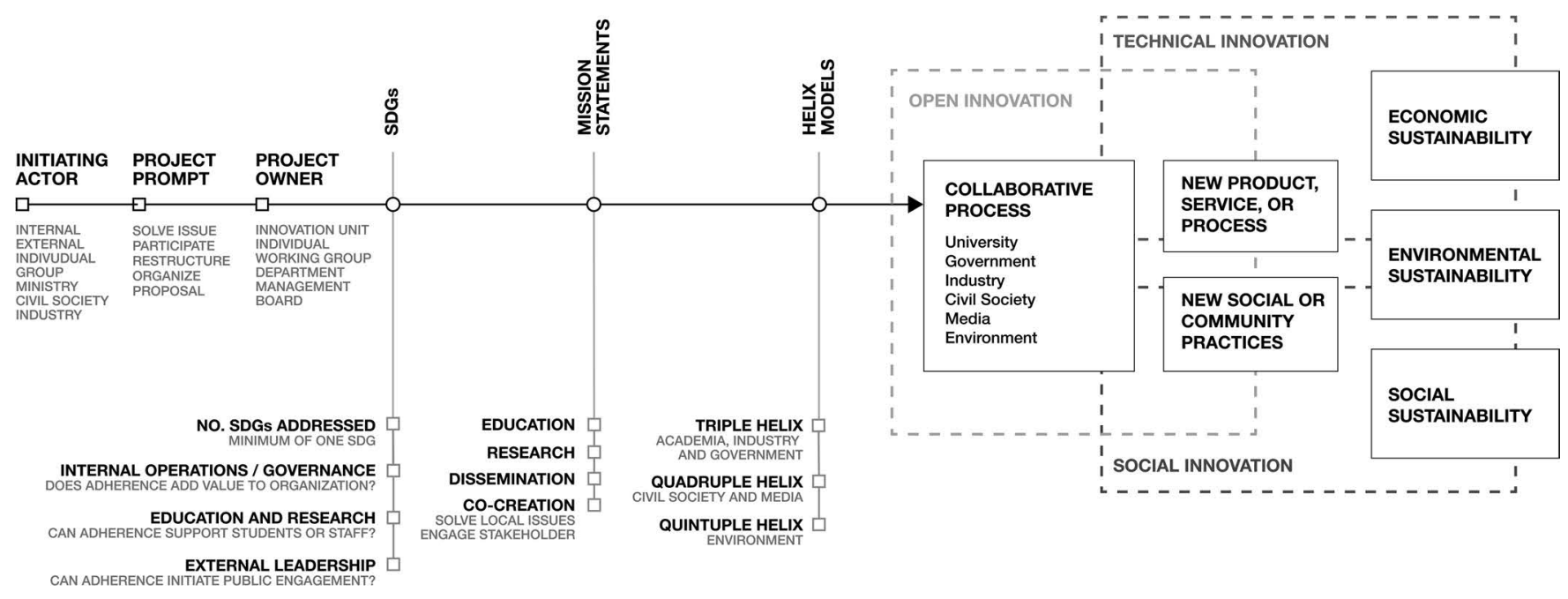

Figure 7.1 Conceptual operational framework. 
and De Souza Bermejo (2014). The structure of the framework is based on common project management tactics and equally assumes a project management approach to its use and function. The flow is fairly straightforward, from left to right, beginning as all projects do, with an initiation that involves ownership and description of the project or process, moving on to an auditing phase where adherence to SDGs, university strategy and collaborative approaches are defined, a processing phase is then initiated where participants follow Open Innovation guidelines in order progress to an output phase - which in turn leads to an impact phase. While important, the initiation phase will not be covered below.

\section{The sustainable development goals}

Since the near-global agreement on the UN's Sustainable Development Goals in 2015, the Faroe Islands have been relatively slow to officially adopt the goals and their targets. While the Faroese government did not officially announce Faroese adherence to the SDGs until February of 2018, interest in- and dissemination of the SDGs was quickly picked up by a few key stakeholders (Government of the Faroe Islands, 2018). Since early 2018, the Prime Minister's Office has been developing a local baseline for the tracking of progress, the University of the Faroe Islands has organised a number of workshops, events, and conferences based on the SDGs, the Municipality of Tórshavn has voted to implement the SDGs as guidelines for future policy work, salmon farmer Bakkafrost has publicly announced an adherence to a number of key goals, and the SDG are often debated and referred to by politicians and stakeholders. Along with these efforts, the University green-lit the establishment of a long-intended cross-disciplinary SDG working group overseen by the Innovation Unit. The work of this group is two-fold: best practices for internal implementation of the SDG throughout the University in terms of daily operations, curriculums, and projects - and simultaneously through external collaborations.

Academic focus on sustainability and sustainable development are not new to HEIs. A very vocal cry for academic engagement with sustainability, in general, has been very visible in the literature since the 1990s and especially since the early 2000s. Definitions of and frameworks for sustainability within HEIs sustainable operations, sustainable research, environmental literacy, ethics, curriculum development, and internal and external multi-helix partnerships and collaborations have already been outlined and analysed many years ago, the use of positive feedback loops and Education for Sustainable Development (ESD) tactics, accountability, assessments and measurements of the impact of sustainability development in HEIs and the use of systems transitions and participatory design processes in relation to stakeholder engagement in relation to HEI sustainability, etc. (Lukman \& Glavič, 2007; Wright, 2002; Godemann et al., 2014; Ferrer-Balas, Buckland, H., \& de Mingo, M., 2008). Much of the recent literature on sustainability 
and sustainable development that has been published after the SDG's launch in 2015 is thematically preoccupied with addressing the Sustainable Development Goals head-on, but in many regards, the arguments and theoretical basis are much the same and build on previous works such as those mentioned.

For the Innovation Unit at the University of the Faroe Islands, the initial question with regards to the SDGs was very binary and simple: "In doing this, are we working against the principles of any of the SDGs?" If the operation or project could be argued to have a negative impact on any of the SDGs, they would be scrapped or reworked. However, in a broader sense, this simplistic way of filtering does nothing to further implementation or garner collaborative support for further development internally or externally, and the need for a proactive stance rather than a reactive one quickly became apparent. In the context of a larger operational framework, the first question we should be asking is: "In doing this, are we furthering the principles of the SDGs - if so, how many and to what extent?" Cross-referencing with a national baseline would, of course, also benefit an initial scoring as this is able to provide far better metrics on the benefits of a certain operation or project. If the answer is positive, we should (as is outlined in SDSN Australia/Pacific, 2017, pp. 10-30) ask ourselves how the operation can contribute to the SDGs through: internal operations and governance, education, research, and external leadership.

This type of early stage evaluation is typical to general project management along with risk assessment and delegation of ownership, but the really beneficial aspect to this type of scoring is that is lends itself to a speedier and more nimble learn-by-doing style of SDG implementation, not unlike Jeff Sutherland's SCRUM methodology (Sutherland, 2014). Rather than spending years developing local implementation guidelines that run the risk of being too unwieldy or dated - an early score-card with simple metrics outlining benefits and drawbacks that allow for easy reporting and quick iterations will allow for better results, the option for broader inclusiveness and collaborations, and an accumulative positive net effect in relation to expertise and know-how down the line. There are, of course, more elaborate and technical ways of assessing the implementation of the SDGs on an academic level. Laurent, A. et al.'s (2019) SDG Assessment Methodology is one such tool.

\section{University strategy and mission statements}

With a solid foundation ensuring adherence to the SDGs and considering their implications as they relate to internal operations, education, research, and external leadership, as seen above, an operational framework is slowly starting to take shape. With the initiating participant having covered ownership and the factoring in of sustainable development goals and targets, it is equally important that they experience there being a willing institutional support toward practical societal contributions within the organisation. 
The three common missions that can be found in most university charters or strategies are education, research, and dissemination. While the University of the Faroe Islands and its staff generally strive to go beyond these three missions, there is no codified or systematic approach to any such operations. Arguing for a systemic approach to academic work that goes beyond these three common missions, I will be relying on Trencher, Yarime, McCormick, Doll, and Kraines' (2013) analysis of an emerging fourth mission they refer to as: co-creation for sustainability. In order to discuss this new type of academic mission, a very brief outline of the missions relating to teaching, research and dissemination will follow below before I return to an analysis. It is important to note that these activities in no way stand-alone within academia, each are pillars supporting the same roof and the same is true for any fourth pillar we might add. Trencher et al. (2013) illustrate this point very well in Figure 7.4 of their paper (Trencher et al., 2013, p. 168).

\section{Teaching}

Growing out of cathedral and monastics schools of late medieval Europe, the first institutions historically to be acknowledged as "universities" were the University of Bologna and the University of Paris, established in the eleventh and twelfth centuries, respectively. The driving force behind these and more than 100 universities that were established around Europe between the twelfth and the fifteenth century, was the expansion of the Catholic Church and the need for a systematised approach to instruct students in matters relating to the church; theology, law, and medicine (Arbo \& Benneworth, 2007, p. 19). This first mission of teaching was to be the main objective of early universities well into and beyond the Enlightenment.

\section{Research}

Following the Enlightenment, a genuine demand for academic reform was raised in the established European academic institutions. As new types of schools and disciplines were developed in order to cater to social changes brought on by the Enlightenment, the French Revolution, the Industrial Revolution, and the growing field of natural sciences - the older institutions were increasingly seen as part of the l'ancien régime of days past. Following the carnage of the Napoleonic Wars, a renaissance was to hit the Prussian academic establishment that would cement the second mission of research as a cornerstone of academia. Brought on by the shuttering of a number of prominent Prussian universities during the wars and a renewed sense of nationalism following the wars, the establishment of the Berlin University in 1810 was guided by the "ideals of Bildung, academic freedom and the collective research process as its corner-stones" (Östling, 2018, pp. 23-9). This notion of Bildung has generally attributed to Wilhelm von Humboldt, and the transition from an academic environment focused purely on teaching, to one 
of teaching and research were to be codified in what became known as the Humboldtian Reform or Humboldtian Model (see Wittrock, 1993; Östling, 2018) which dictated a more holistic approach to academic education where students were given academic autonomy to pursue their interest and engage with the world through reason and self-determination. Within this ideal, the pursuit of knowledge was to be available to all and aim to change the world for the better independently of economic interests. In other words, knowledge for the sake of knowledge (see Östling, 2018; Anderson, 2004).

\section{Dissemination and technical transferal}

While the third mission encompasses academic dissemination to peers and the public in a variety of forms not covered by the first and second missions, the focus here is rather on the technical transferal of knowledge for use outside of the academic realm (E3M Project, 2012). The rise of this part of the third mission emerged from Vannevar Bush, 1945 conceptualisation of a "university-industrial complex" following the World War 2 (Bush, 1945). Bush's blueprint for academia was meant to "establish a link between university research and business innovation" in order to "advance economic well being" (Zomer \& Benneworth, 2011, p. 83). As Clark (1998) and Etzkowitz (2002) point out, the connection between academia and industry within a third mission formulation dates back to the European agricultural universities and the American land-grant universities of the Industrial Revolution. However, Bush's university-industrial complex did not pick up speed until the 1980s, helped along with the passing of the Bayh-Dole Act of 1980 that allowed researchers to claim ownership of federally funded inventions and technical advancements through patents (Mowery, 2007 as cited in Trencher et al., 2013). This new law was instrumental in capitalising, commercialisation, and commodification of knowledge (Zomer \& Benneworth, 2011, p. 84; Etzkowith, 1998, p. 826). This commodification, in turn, gave rise to the Entrepreneurial University (see for example: Clark, 1998; Etzkowitz, 1998; Etzkowitz, Webster, Gebhardt, \& Terrad, 2000), where external funding often dictates the direction of research and applied sciences in order to maximise profits outside of the university. Led by MIT and Stanford-for the Entrepreneurial University, "identifying, creating and commercialising intellectual property have become institutional objectives [with the aim of] improving regional or national economic performance as well as the university's financial vantage and that of its faculty" (Etzkowitz et al., 2000, p. 313 as cited in Trencher et al., 2013, p. 151).

It should be noted here that technical transferal of knowledge in the form of patents or products might not be relevant to the majority of smaller Arctic universities. In cases where this commercial component is missing or lacking, the argument for an organisational focus on social issues such as sustainability would be a much simpler sell as that addition of the next mission we will deal with will show. 


\section{Co-creation for sustainability}

As is argued by Trencher et al. (2013, pp. 156-157), the term "social contribution is a useful synonym for describing the core notion of the third mission." However, they go on to argue that "the idea of societal contribution is today widely perceived and promoted as being chiefly an economic contribution" championed by OECD efforts to "emphasize the economic benefits and gains in international competitiveness for governments when universities focus their third-stream activities on innovation transfer and spurring regional development" (Trencher et al., 2013, pp. 156-157). In their critique of the third-mission regime, Trencher et al. (2013) conclude that efforts to introduce the concept of sustainability and green innovation into the existing third mission has yet to produce much in the way of results-likely due to the fact that the majority of funding and knowledge transfer relates to medicine, biomedical- and computer research. Based on their analysis of the current state, their "position is that the potential of the third mission regime to function as a useful guiding concept or propelling force in the quest for low-carbon development and sustainable transformation of individual towns, cities, and regions is yet to be proven" (Trencher et al., 2013, pp. 156-157). They (Trencher et al., 2013, pp. 157-9) then argue for a fourth mission statement, one of co-creation for sustainability. They do not argue that this new mission should supplant the third mission, but rather supplement it in compounding the effects of all four mission statements by transforming Entrepreneurial Universities into Transformative Universities (Trencher et al., 2013, p. 169, emphasis is of the author) that weave together: teaching, research, dissemination, and co-creation for sustainability. This mission, they argue (Trencher et al., 2013, p. 158) is one that requires the transformative university to encompass a broad range of transdisciplinary sciences working together long-term on crucial issues that are place and stakeholder oriented. Further, they call for large-scale coalitions with multi-helix specialists and non-specialists utilising Open Innovation tactics in order to produce socially embedded knowledge and mutual learning. To clarify, let us take a look at Helix models and Innovation frameworks in turn.

\section{Helix models}

If the Berlin University of 1810 could be said to be Single Helix and the addition of industry to form the Entrepreneurial University of the 1980s could be said to be a Double Helix, then the addition of government as a third actor is what makes up the Triple Helix Model. Conceptualised by Etzkowitz (1993) and Etzkowitz and Leydesdorff (1995) in an effort to interpret the shift from a dualistic relationship between universities and industry in the industrial society, to the triadic relationship between academia, industry, and government in the modern knowledge society, the Triple Helix Model is commonly seen as the standard for modern academic cooperation. 


\section{Triple Helix}

Often depicted as three intertwined strands in the style of the classic representation of DNA, the Triple Helix model is probably better illustrated in the style of a Venn diagram consisting of three circular spheres of influence; academia, industry, and government overlapping. Since Etzkowitz and Leydesdorff's early work of the 1990s, an abundance of theoretical development has pushed the conceptual framework of the model forwards immensely and we will not be able to gain a complete overview of the literature here. A majority of the early literature is concerned with the in-depth analysis of systemic and organisational interactions at fairly large scales where actors tend to be portrayed as entire universities, entire companies or entire governments-often ignoring the roles of individual actors such as members of staff or specialised working groups. While much of the early theoretical work on the topic provides a good foundational approach to how these three spheres of influence can come together, they do not, however, "provide an explicit analytical framework for conceptualizing Triple Helix interactions in an innovation system" (Ranga \& Etzkowitz, 2013, p. 238) and the large-scale holistic focus on "'block' entities, without going deeper to the level of sphere-specific actors" (Ranga \& Etzkowitz, 2013, p. 242) are not conducive to the Arctic conditions dealt with here. For the sake of the operational framework, I will be relying on Ranga and Etzkowitz's (2013) more fine-grained analysis of the Triple Helix systems approach below.

In very broad strokes, the conventional theoretical approach to the Triple Helix model is based on two complementary perspectives; one institutional and one evolutionary. Within the institutional approach, the way the three spheres of influence interoperate fall into three different configurations: $A$ statist configuration, where the government acts as the main driver and planner for innovation and development. A laissez-faire configuration with limited governmental control is where the industry is the main driver and universities provide skilled workers. And, a balanced configuration where the institutions act jointly in formalised partnerships (Ranga \& Etzkowitz, 2013, p. 239; Etzkowitz \& Leydesdorff, 2000, p. 111). For our sake, my references to the Triple Helix model will refer to the balanced configuration where trilateral networks and hybrid organisations are possible (this is also similar to the notion of Triple Helix type 3 as noted by Etzkowitz \& Leydesdorff, 1998, p. 197). The evolutionary perspective argues that universities, industry, and government exist and co-evolve within social systems where they are influenced by markets, technological advancement, environmental concerns, and so on. The interoperation between the stakeholders here relies heavily on two processes of communication - a functional and indirect one between science and markets, and an institutional and direct one between private and public control that allows for selective adjustments that ensure a regeneration of the system (Ranga \& Etzkowitz, 2013, p. 240). Especially the move from Triple to Quadruple and Quintuple Helix is very much contingent on the view that 

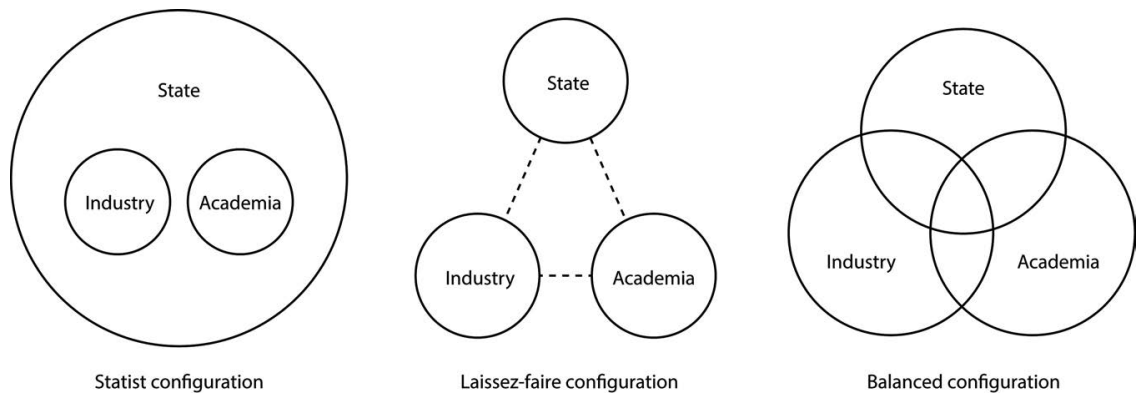

Figure 7.2 The three different configurations of the way the three spheres of influence interoperate in the institutional approach.

stakeholders must operate within a social system of change through individual actors that are able to set up lines of communications and work together in order to adjust and reshape the system.

Ranga and Etzkowitz (2013, pp. 241-254) break down the conventional understanding of the Triple Helix model using the innovation systems concept or, as it was later known; national innovation systems (NIS) (Ranga \& Etzkowitz, 2013, pp. 240-241) in order to analyse it at a more granular scale. Their Triple Helix systems approach breaks down the Triple Helix model into three elements: First, system components (and their boundaries), these are the institutional spheres of university, industry, and governmentconsisting of the institutional actors themselves and any individual actors, and where these networks overlap. While the institutional actors can, as such, be argued to interact - the interest here is rather on the individual actors involved; innovational initiators, entrepreneurial researchers, $R \& D$ staff, the management or policy writers. Second, relationships between the system components, meaning direct collaboration, conflict moderation, collaborative leadership, and so on. It is through meaningful and carefully moderated relationships that actors are able to work together, transfer knowledge, network and replicate the system. Third, the functions of the system, relate to the generation, diffusion, and use of knowledge and innovation as an absolute main ideal. This is the end product of the model, the coming together of different stakeholders in order to produce and disseminate new knowledge that can be utilised to benefit a greater need.

Ranga and Etzkowitz (2013, pp. 247-250), however, argue that in order to get to this end product, it will need to be realised through what they call Triple Helix spaces: the Knowledge Space, the Innovation Space, and the Consensus Space. Very much relevant to our operational framework, they can, in an Arctic low-resource context, be understood as follows: The Knowledge Space is where an aggregation of local and regional research and knowledge exists. This could take the form of a local database managed by local research councils, tracking the output and needs of universities, industry, and government in order to ensure that research is not fragmented or needlessly 
duplicated. ${ }^{2}$ Up to date data on the knowledge being produced and governmental or municipal projects needing attention could help streamline collaboration. The Knowledge Space should also aim to attract funding and leading research through networking and dialogue. The aim of the Innovation Space is to provide a common platform for stakeholders to manage the development of new and innovative firms and industries. This can be done through the creation of integrated environments where academia, research, and the needs of industry, governments, and municipalities can come together in order to find solutions. The Consensus Space is a coming together of stakeholders into a forum where they are interdependent and can begin to see themselves as part of something greater than their department, company, town, or country. This can take the form of brainstorming meetings and dialogue sessions that aim to solve issues that are not solvable by any one sector of society, such as housing shortages, unemployment, pollution etc.

\section{Quadruple Helix}

If we reconsider the earlier steps in this proposed framework, the academic mission statement of co-creation for sustainability is predicated on the collaboration between academia, industry, government - and also civil society

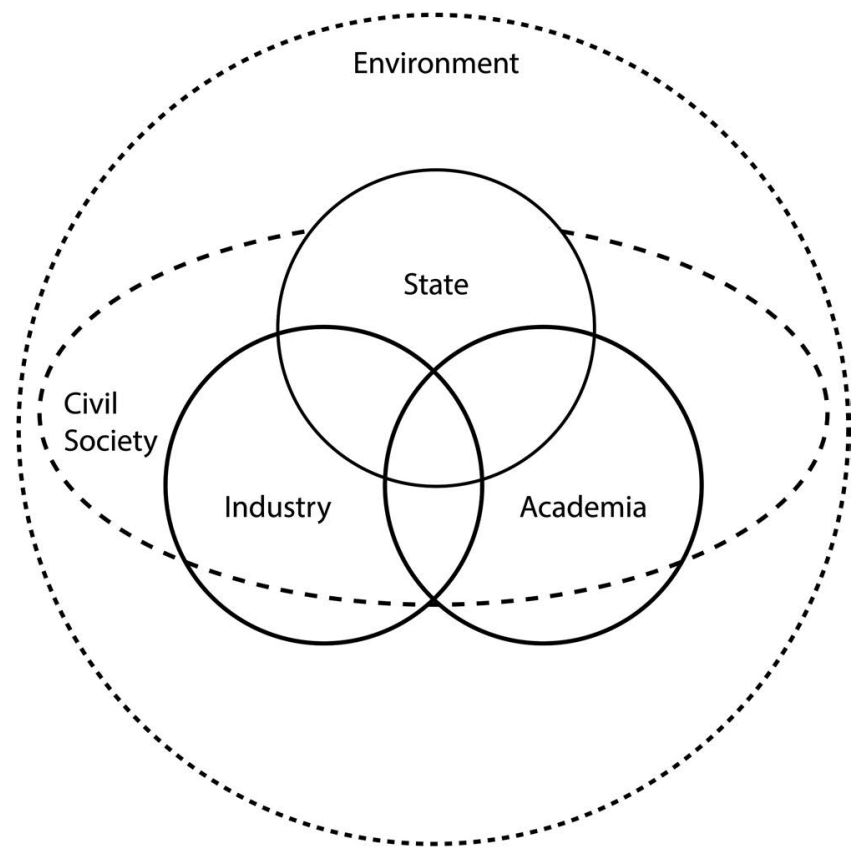

Quintuple Helix Model

Figure 7.3 Quintuple-Helix model. 
and the media. This broad and inclusive approach is very much in line with the arguments made by Carayannis and Campbell (2009, pp. 206-207) for a fourth dimension to the existing Triple Helix model, and it is similarly very close to the evolutionary perspective of the triadic arrangement of academia-industry-government needing to exist within a malleable and changing social system and not a theoretical vacuum (Ranga \& Etzkowitz, 2013, p. 240). For Carayannis and Campbell (2009, pp. 206-207), a Quadruple Helix model considers the necessity of the media as a means to transport public discourse and playing a vital role in the communication of social realities, norms, and values. Adding to that, a Quadruple Helix model also incorporates the actions of agents of culture, civics, and arts within the community. As such, the Quadruple Helix model is easily able to accommodate the Helix spaces mentioned above, and there are no practical barriers to the inclusion of NGOs, interest groups and cultural movements. This inclusiveness has the possibility of, as Carayannis and Campbell (2009, p. 207) argue, result in a "democracy of knowledge, driven by a pluralism of knowledge and innovation $[\ldots]$. "

\section{Quintuple Helix}

Returning to the Sustainable Development Goals and their focus on sustainable development and ecological stewardship, there is yet another Helix Model that concerns itself with these issues. Building on their argument for a Quadruple model, Carayannis and Campbell (2010) go on to argue for the fifth sphere of influence; the environment. While the Triple- and Quadruple Helix models concern themselves mainly with economic and cultural innovations and gains, the Quintuple Helix model adds elements of sustainable development and social ecology, and ultimately argues that this added level of the model has the ability to structure the Helix model approach in such a way that it can allow stakeholders to concern themselves with eco-innovation and eco-entrepreneurship (Carayannis \& Campbell, 2010, pp. 58-63).

\section{Innovation frameworks}

While the three different Helix Models outlined above concern themselves with variations of theoretical and practical takes on collaboration and innovation, there are two further conceptual manifestations of innovation that can be favorably considered in this context. At one end, we have the profit maximisation of Open Innovation - and on the other end, the maximisation of social good inherent in Social Innovation. While these initially seem diametrically opposed, I hope to make a convincing argument that by combining these two approaches to innovation at the tail end of a framework an Open Social Innovation approach to innovation might have a useful role to play in making sustainable development viable within the Arctic. 


\section{Open innovation}

The initial ideas relating to open innovation date back to the 1960s onset of the Information Age and the spread of computers, but the formalised term used in reference to industry opening up their silos of research and development to external researchers and developers in order to licence, spin out, and divest products was conceptualised and coined by Henry Chesbrough in 2003. While Chesbrough's (2003) initial conceptualisation was heavily slanted toward accelerated development of new technologies and goods by making an organisation's boundaries more permeable and hopefully more profitable, later refinements of the term argue that the process can also be a useful way of managing the flow of knowledge across organisational boundaries both internally and externally simultaneously using "pecuniary and non-pecuniary mechanisms in line with the organization's business model" (Chesbrough \& Bogers, 2014) - that is, measured in both monetary and non-monetary terms.

In short, Chesbrough and Bogers (2014) argue that Open Innovation is based on the premise that the drive for innovation and the sources of knowledge that can drive innovation are dispersed widely in society and the economy. They invoke Bill Joy's (co-founder of Sun Microsystems) Law that states that "most of the smartest people work for someone else" (Chesbrough $\&$ Bogers, 2014). Open Innovation, briefly, is a way to scale the boundaries of otherwise closed-off organisations in order to allow for novel approaches to stagnant problems by outside expertise. In practice, this involves industry establishing an Open Business Model (Vanhaverbeke \& Chesbrough, 2014) that is inclusive to external stakeholders and innovators. This type of model sets up a "division of innovation labour" where one party might research and develop a new idea - and another party, in turn, carries it to market (Vanhaverbeke \& Chesbrough, 2014, pp. 52-53). Vanhaverbeke and Chesbrough (2014, p. 54) give a number of examples of how this approach can be useful; inside-out modes that result in licensing agreements and spin-offs, outside-in modes that draw in external expertise and combine it with an existing business model and modes where an industry makes use of external or internal knowledge to develop entirely new business models. While Chesbrough's definition of the term is generally applied to a commercial setting - the notion that very capable and innovative actors are to be found outside the boundaries of an organisation is just as likely to hold true to non-commercial organisations such as a university, a municipality or an NGO. While the literature on Open Innovation is too broad and varied to cover here, this main takeaway of being able to look beyond institutional and organisational walls for expertise and inspiration is the key. While the more typical combination of Open Innovation and academia is fairly commonplace at many technical universities and business schools around the world - applying the same mindset of openness that a business might employ to further commercial interest to an academic reality allows 
for even more and more diverse collaborative arrangements when combined with the tenets of Social Innovation. Especially for small non-technical Arctic universities, when combined with the fourth mission statement of co-creation for sustainability and a strong multi-helix approach, the concept of Open Innovation is easily transformed from a profit-making industry strategy into an academic collaborative approach based on openness and stakeholder inclusion. By utilising Open Innovation as a core strategy, the operational framework allows the university and its stakeholders to move forward both in a conventionally technical innovation track, or it can use the same tactics to focus its energy on maximising social good through Social Innovation. Further, Open Innovation when employed from the perspective of a university can even facilitate technical and social innovation in parallel - facilitating the development of a viable new product or service based on social issues. The majority of literature dealing with Open Innovation deals with how it benefits Technical Innovation, so I will not be covering it here. Its exclusion should, however, not be seen as it being of lesser interest or importance to the framework. For the sake of understanding how small institutions can better target social issues, we will concern ourselves with the value of Social Innovation and how Open Innovation can be used as an important tool to realise social innovation-based projects.

\section{Social innovation}

Open Innovation is, at least from a theoretical standpoint, very much tied to business innovations which in turn are motivated by profit maximisation. Social Innovation, on the other hand, is predominantly motivated by the goal of meeting social needs (Mulgan, 2006, p. 146). Social Innovation can be defined as "innovations that are social both in their ends and their means. [They are] new ideas (products, services, and models) that simultaneously meet social needs and create new social relationships or collaborations. In other words, they are innovations that are both good for society and enhance society's capacity to act" (Murray and Mulgan, 2010, p. 3).

A very different aspect to Social Innovation, as opposed to innovation in a more broad sense, is that Social Innovations need not be wholly new ideas-but can be new to those benefiting from them. Further, Social Innovations tend not to be inherently new in and of themselves, but rather a combination of already available technologies or solutions (Mulgan, 2006, p. 151). Boelman and Davies (2015, p. 6) also argue for this newness criteria along with the requirements that Social Innovations should meet a social need in positive ways, they should be put into practice, they should engage and mobilise beneficiaries through governance and they should transform social relations through greater access to power and resources. They further argue that Social Innovations (Boelman \& Davies, 2015, p. 7) can take many different forms; new services, products, practices, processes, rules, regulations, and organisational forms. 


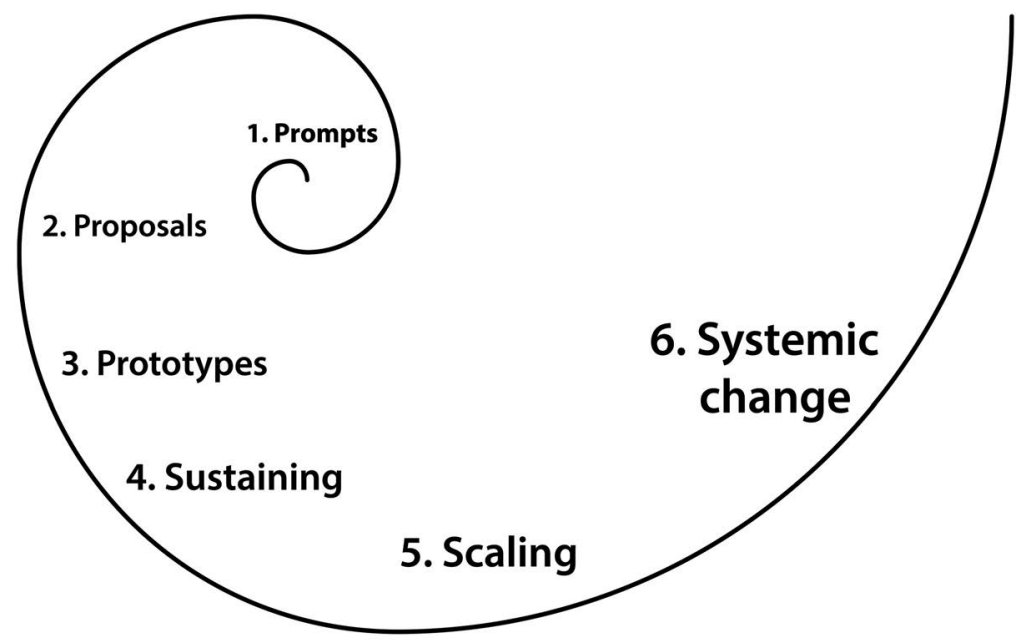

Social Innovation stages

Figure 7.4 Social innovation stages.

A core distinction between Open Innovation and Social Innovation, is that Social Innovation aims to solve issues not generally solved by commercial interests (Nicholls, Simon, Gabriel, \& Whelan, 2015, p. 3). They can be issues such as human rights, environmental concerns, healthcare, or education - often in developing or remote regions of the world. According to Murray and Mulgan (2010) and Rayna and Striukova (2019) the Social Innovation process can be broken down into six different stages:

1 Prompts, inspirations, and diagnoses: Initial stage during which various factors trigger the need for innovation, after which a diagnostic of the problem and the framing of the question ensue.

2 Proposals and ideas: Idea generation stage using a variety of methods based on insight and experience.

3 Prototyping and pilots: Stage during which ideas are put into practice to be tested and, subsequently, refined.

4 Sustaining: Stage at which the idea is adopted for everyday use and is, as a result, streamlined. Income streams are identified at this stage.

5 Scaling and diffusion: Stage at which there is an attempt to scale up and diffuse the innovation beyond its original test bed.

6 Systemic change: This stage is the ultimate goal of social innovation, but also the most difficult to achieve due to its wide-scale, the large number of stakeholders it involves and the multiple barriers to change that exist. 
Of these six stages, the first three are relatively straightforward even in resource-poor situations and areas. Broadly they rely on idea generation as a response to social issues that can be undertaken by even small groups of people or even individuals. In a small-scale academic setting, this is generally how far a group of students would be expected to be able to push a project for an assignment or the level of refinement a group of independent volunteers might be able to develop a project funded by a small municipality or government (of which I have taken part in more than my fair share). It is only in the last stages of the innovation process that any meaningful impact will be seen. The main reason for failure at steps 4 and beyond is often the obvious lack of income streams for projects that aim to do social good in areas where there tends to be little in terms of economic value. While these types of small-scale projects can be a good way to illustrate proofs-ofconcept (free communal urban gardens, for example), they quickly tend to fizzle out after only a short time due to a lack of resources.

Another, perhaps not so obvious, reason for failure at this crucial point in the process is often the absence of supportive networks. Mulgan (2007) and Rayna and Striukova (2019) point out that failures to connect with networks that can provide expertise and experience are a common pitfall for social innovation processes. Similar to how the industry might employ Open Innovation as a means to entice external expertise into the fold - they argue that this is a tactic that could be extremely applicable in terms of bringing social innovation to market, so to speak. Rayna and Striukova (2019, p. 385) argue that "[b]y enabling access to a larger pool of resources and skills, as well as diffusion paths, applying open innovation paradigm to social innovation could enable to overcome critical challenges at all six stages of the social innovation process.”

\section{Open social innovation}

I have argued that Open Innovation and Social Innovation are two rather different strands of innovation frameworks that serve very different needs. Yet the similarities of bringing products to market tie the two processes together in more ways than one. In both cases, maximising profits and maximising social good, the processes hinge on networking, external expertise, and novel business models. While commercial enterprises make use of business models in order to turn a profit, social innovations will ultimately have to rely on some form of operational resources (likely in the form of monetary funding) in order to sustain themselves and in turn scale, diffuse and enact systemic changes.

The concept of Open Social Innovation seems to be first proposed by Dominic Chalmers (2013). In his article, he argues for similarities between the Open and Social Innovation similar to the ones noted above. As argued above, some main reason for failures to launch social innovation processes are lack of long-term operation resources and a lack of expert networking. 
Chalmers expands upon the knowledge searching and networking issues by arguing that social innovators would do well to focus more on their users as well as initiating boundary-spanning knowledge searches that look for expertise and innovation that exist beyond their organisation's traditional domains to combat "industry blindness" (Chalmers, 2013, p. 25).

Chalmers (2013) goes on to identify a third stumbling block (related to resources) that is common for social innovation processes; risk aversion. He argues that a common barrier "to the adoption of social innovation lies in the risk associated with disruptive innovation [in that] those offering support to social innovators in the form of capital are institutionally conditioned to favour incremental 'safer' forms of innovation" (Chalmers, 2013, p. 26). In order to combat risk aversion, Chalmers argues for five different propositions for social and community-based organisations (Chalmers, 2013, pp. 27-28):

1 Adopting a more "open" approach will mitigate risks associated with introducing new innovations.

2 Adopting problem solutions from different domains will reduce the risk of new innovations failing.

3 Incorporating user knowledge into the innovation process will increase their chances of success.

4 Participating in some form of open, networked innovation will be more effective at developing innovations addressing the root causes of social problems.

5 Engaging in "open source" collaboration will be more effective in tackling vested interests and dominant competitors.

Here we see the beginnings of merging of Open and Social Innovation. In applying Open Innovation mechanisms to the issues facing Social Innovation, social innovators should adhere to a networking paradigm that involves multiple boundary-spanning stakeholders-which in turn would help mitigate risk aversion from investors and funders.

Martins \& De Souza Bermejo (2014) follow up on Chalmers work and argue as the main point that "when Social Innovation is seen from a collaborative point of view, organizations become more porous structures that make it possible to overcome the barriers that prevent communities from innovation from the bottom up. Thus, when organizations are open they strengthen localism and provide a means for civil society to become involved in finding solutions" (Martins \& De Souza Bermejo, 2014 ). They go further to attempt a conceptual model of the relationship between Open Innovation and Social Innovation seen in Figure 7.5.

They argue that the collaborative interplay between Open and Social Innovation not only has the capacity to produce new solutions to social problems and changes to social practices, but at the same time is also able to facilitate and stimulate new technical innovations in the form of new 


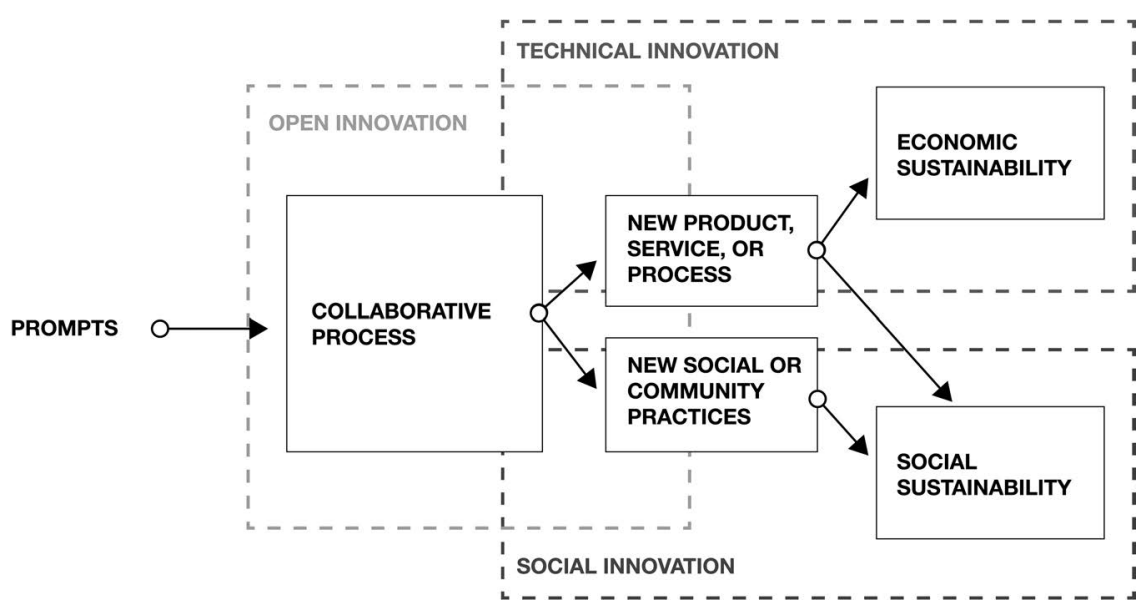

Figure 7.5 Conceptual model of the relationship between open innovation and social innovation.

products, services or processes that in turn result in economic development. At the same time, Chesbrough and Di Minin (2014, p. 170) venture a definition of the concept. They defined Open Social Innovation (OSI) to be "the application of either inbound or outbound open innovation strategies, along with innovations in the associated business model of the organisation, to social challenges" (Chesbrough \& Di Minin, 2014, p. 170). They argue that Open Social Innovation is especially apt at solving stages 3-5 of the Social Innovation process (Chesbrough \& Di Minin, 2014).

Regardless of where the prompt originates; industry, government, academia, or civil society - social innovation and socially innovative projects more broadly will mostly follow the six steps outlined above. They will need to pass through a phase of idea generation, prototyping, and testing phase, and eventually a process of sustaining itself so that it can scale and hopefully change society for the better. Most of these socially conscious community-based efforts at social change will likely struggle to move beyond the initial prototyping and proof of concept stages due to the lack of operation resources. And as Chalmers (2013) argues, it can be hard to find funding for risky disruptive innovation aimed at a segment of society that might not be seen as very profitable, politically incorrect or otherwise unpalatable for whatever reason.

Before moving on the how this might look from an academic perspective, I hope that (albeit brief) the arguments for utilising Open Innovation tactics in conjunction with Social Innovation processes will seem compelling. How they can be made to push Social Innovation initiatives beyond stages of initial prototyping and proof-of-concept, how they can mitigate risk and how they can break down institutional borders and 
attract external expertise. None of the examples used so far have concerned themselves with academia. They have all focused on industry and NGOs. What is wholly absent from the literature is a perspective from within academia. In the following concluding section, I will attempt to outline why I think the framework presented is such a natural fit for small Arctic universities.

\section{An academic perspective}

As I have noted above, Open and Social Innovation tactics are generally considered to belong in the domains of commercial enterprises and actionoriented civic groups such as NGOs or governmental agencies. Only in rare instances does the literature attempt to shine a light on how these tactics could be employed by academia in an effort to pursue issues of sustainability, innovation, entrepreneurship, or social change. The University of the Faroe Islands is comparable to a number of Arctic universities. It is a small, publicly funded university servicing around 800 students in five different departments. Apart from offering courses in social sciences, economy, law, natural science, and Faroese, it also houses a teacher's college and a degree in nursing. In relation to mainland Europe and the Arctic region broadly, it is a geographically isolated university with a relatively low level of contact with other institutions of higher learning in the region.

At the time of writing, the University is facing a number of issues. It is seeking to modernise, systematize, and professionalise a wide array of operational aspects of the organisation; this includes the development of a new university strategy and updated mission statements. It is also attempting to broaden its local, regional, and international reach in terms of collaborations, research networking, and funding - all with very limited resources. Further, the university is also reacting to the emerging trends within the Arctic academic environment described above (Blaxekjær et al., 2018). The small size of the University of the Faroe Islands and other similar universities in the Arctic that often exist to service the local population and seldom profile themselves in a manner that would attract an international student body or sizeable amounts of external funding, must often make do with local networks and draw on local sources of funding for research-or relegate themselves to taking on smaller and often non-technical roles within larger European or Arctic research projects.

The current lack of much international research presence facing many of the smaller Arctic universities does, however, allow them to occupy academic niche positions relating to local knowledge and development. This hyper-specialisation and localisation of knowledge has, especially in recent years, become a growing trend within the Arctic and often sees small Arctic universities being able to punch above their weight, participating in a much more level footing on their home turf due to valuable local insights and expertise. Coming to terms with how valuable these smaller universities are 
to their local communities and how much social good they are able to initiate through socially conscious activities would not only maximise organisational output, but it would also have the added benefit of building up local competences and credibility with regards to regional and international collaborations.

In order to operate optimally, an operational framework such as the one presented here would need to be functional on a number of levels in order to deliver practical lasting results. If the output is to be sustainable social innovation, it must cover the three general aspects of sustainability - economic, environmental and social. To reach that level, it must, therefore, encompass some form of technological innovation that creates local jobs or adds positively to the economy in the form of new products or services and it must also contain an element of social innovation that results in new sustainable practices or developments. However, in order to have commercial and social innovations complement each other in a sustainable way, university lead initiatives will need to rely on a collaborative process with industry on one side and civil society and government on the other. This process, the Innovation Unit argues, fits perfectly with the mechanisms of Open Innovation. It is here that university-led Open Innovation is able to facilitate openness, dialogue, networking, risk and stakeholder management, and a collaborative effort to push projects beyond stages four and five of the social innovation track.

To get to a point where this facilitation of sustainable development between academia, industry, and civil society becomes possible, the university must progress through a preparatory phase of internal auditing that ensures the inclusiveness of stakeholders, the strategic value for the university and a strict adherence to sustainability throughout the process. Before the Open Innovation tactics can be utilised in an open, collaborative process, the university and key stakeholders should conduct a Helix-model audit. Following a Triple Helix model stakeholders would only include academia, government, and industry (Etzkowitz, 1993; Etzkowitz \& Leydesdorff, 1995). Using a Quadruple Helix model would include civil society in the process (Caryannis \& Campbell, 2009). Even better, by utilising a Quintuple Helix model the university is able to include a fifth sphere of influence: the environment (Caryannis \& Campbell, 2010). A prerequisite for successful Helix model collaborations led by the university is of course that the university takes on an active and participatory role. In order for the university to do so, projects must have a strategic value that complement university missions statements of education, research, and dissemination. In order to boost impact, the Innovation Unit advocates that the university goes beyond these three common mission statements and initiates a fourth mission statement of sustainable co-creation as is put forward by Trencher et al. (2013). As noted above, there is a clear wish from a number of Arctic universities that the UN Sustainable Development Goals be implemented as a guiding framework for curricula and daily operations. If the output of this 
operational framework is to be sustainability in its different forms, then the SDGs are currently likely the best way to audit the sustainability of initiatives. The SDGs are simple, easy to understand, give participants a common language through their goals and targets and are at the same time not very confrontational as a tool. As a yardstick, simply asking whether a project or an initiative would be counter to the tenets found in the SDGs would be a good start. If so, it should be reconsidered or scrapped. If a project is not counter to the SDGs, an audit and analysis of how well the project is in line with the SDGs, how many goals and targets it will cover and a measurement of impact should be produced. Also, the university should consider how participation in the project or initiative and subsequent adherence to the SDGs might positively impact internal operations and governance of the organisation and the institution, how it might be used for educational purposes, for research purposes - and how it might be used as a way for the university, along with stakeholders, to illustrate leadership and commitment toward sustainability within the community.

At the time of writing, the Innovation Unit at the University of the Faroe Islands is further developing the framework and lobbies for it to be implemented as a way to assess upcoming projects and processes. It is our firm belief that a structured and theoretically sound approach to social issues will allow the university to present itself as an open, inclusive stakeholder and champion of sustainability in the Faroese Islands.

\section{Notes}

1. At the time of publishing the Innovation Unit (now formally the Research and Enterprise Unit) has chosen to initially focus on mission two (research).

2. www.isaaffik.org is one such initiative.

\section{References}

Anderson, R. D. (2004). European Universities from the Enlightenment to 1914. Oxford Scholarship Online.

Arbo, P., \& Benneworth, P. (2007). Understanding the Regional Contribution of Higher Education Institutions: A Literature Review. OECD Education Working Papers, No. 9. https://doi.org/10.1787/161208155312

Arctic Council. (2016). Arctic Resilience Report. http://hdl.handle.net/11374/1838

Boelman, V., \& Davies, A. (2015). Growing Social Innovation: A Guide for Policy Makers. http://youngfoundation.org/wp-content/uploads/2015/04/YOFJ2786_ Growing_Social_Innovation_16.01.15_WEB.pdf

Bush, V. (1945). Science: The Endless Frontier: a Report to the President by Vannevar Bush, Director of the Office of Scientific Research and Development, July 1945. www.nsf.gov/od/1pa/nsf50/vbush1945.htm

Caryannis, E., \& Campbell, D. (2009). "Mode 3" and "Quadruple Helix": Toward a 21 st century fractal innovation ecosystem. International Journal of Technology Management, 46, 201-34. 
Caryannis, E. G., \& Campbell, D. (2010). Triple helix, quadruple helix and quintuple helix and how do knowledge, innovation and the environment relate to each other? A proposed framework for A trans-disciplinary analysis of sustainable development and social ecology. International Journal of Social Ecology and Sustainable Development, 1(1), 41-69.

Carayannis, E. G., \& Campbell, D. (2012). Mode 3 knowledge production in quadruple helix innovation systems. Springer.

Carayannis, E. G., Barth, T. D., \& Campbell, D. F. J. (2012). The quintuple helix innovation model: Global warming as a challenge and driver for innovation. Journal of Innovation and Entrepreneurship, 1(1), 2.

Chalmers, D. (2013). social innovation, an exploration of the barriers faced by innovating organizations in the social economy. Local Economy, 28(1), 17-34.

Chiu, R. (2012). Entrepreneurship education in the Nordic countries: Strategy implementation and good practices. Nordic Innovation Report, 24.

Chesbrough, H. (2003). Open innovation: The new imperative for creating and profiting from technology. Harvard Business School Press.

Chesbrough, H., \& Bogers, M. (2014). Explicating open innovation: Clarifying an emerging paradigm for understanding innovation. In H. Chesbrough, W. Vanhaverbeke, \& J. West (Eds.), New frontiers in open innovation (p. 3-28). Oxford University Press.

Chesbrough, H., \& Di Minin, A. (2014). Open social innovation. In H. Chesbrough, W. Vanhaverbeke, \& J. West (Eds.), New frontiers in open innovation, (p. 169-188). Oxford University Press.

Clark, B. R. (1998). Creating entrepreneurial universities: Organization pathways of transformation. Pergamon.

E3M Project. (2012). Green Paper: Fostering and Measuring "Third Mission" in Higher Education Institutions. www.esna.tv/files/div/GreenPaper_ThirdMission.pdf

Etzkowitz, H. (1993). Enterprises from science: The origins of science-based regional economic development. Minerva, 31, 326-60.

Etzkowitz, H. (1998). The norms of entrepreneurial science: Cognitive effects of the new university-industry linkages. Research Policy, 27, 823-33.

Etzkowitz, H. (2002). MIT and the rise of entrepreneurial science. Routledge.

Etzkowitz, H., Webster, A., Gebhardt, C., \& Terrad, B. R. C. (2000). The future of the university and the university of the future: Evolution of ivory tower to entrepreneurial paradigm. Research Policy, 29(2), 313-330.

Etzkowitz, H., \& Leydesdorff, L. (1995). The triple helix, university-government relations a laboratory for knowledge based economic development. EASST Review, 14(1), 14-19.

Etzkowitz, H., \& Leydesdorff, L. (1998). The triple helix as a model for innovation studies. Science and Public Policy, 25(3), 195-203.

Etzkowitz, H., \& Leydesdorff, L. (2000). The dynamics of innovation: From national systems and "Mode 2" to a triple helix of university-industry-government relations. Research Policy, 29(2), 109-23.

Ferrer-Balas, D., Buckland, H., \& de Mingo, M. (2008). Explorations on the university's role in society for sustainable development through a systems transition approach: Case study of the technical university of Catalonia (UPC). Journal of Cleaner Production, 17, 1075-1085.

Godemann, J., Bebbington, J., Herzig, C., \& Moon, J. (2014). Higher education and sustainable development: Exploring possibilities for organisational change. Accounting, Auditing \& Accountability Journal, 27(2), 218-33. 
Government of the Faroe Islands. (2018). United Nations Sustainable Development Goals. The Government of the Faroe Islands. https://www.government. fo/en/the-government/ministries/prime-ministers-office/united-nations-sustainabledevelopment-goals/

Laurent, A. et al. (2019). UN SDG Assessment Methodology and Guideline: Version 1.01. Quantitative Sustainability Assessment Group, Technical University of Denmark, Kgs.

Blaxekjær, L. O., Olsen, M. M., Thomasen, H., Gleerup, M. T., Lauritsen, S. N., Kappel, A. L. ... Friedlander, J. (2018). The sustainable development goals and student entrepreneurship in the Arctic. In L. Heininen, H. Exner-Pirot, \& J. Plouffe (Eds.), Arctic yearbook 2018 - Arctic development: in theory and in practice. Northern Research Forum.

Leydesdorff, L., \& Etzkowitz, H. (1998). The triple helix as a model for innovation studies. Science and public policy, 25(3), 195-203.

Lukman, R., \& Glavič, P. (2007). Review of sustainability terms and their definitions. Journal of Cleaner Production, 15(18), 75-85.

Martins, T. C., \& De Souza Bermejo, P. H. (2014). Open social innovation. In Ć. Dolićanin et al. (Eds.), Handbook of research on democratic strategies and citizen-centered e-government services, p. 144-163. IGI Global.

Mulgan, G. (2006). The process of social innovation. Innovations, 1(2).

Mulgan, G. (2007). Social Innovation: What It Is, Why It Matters and How It Can Be Accelerated. https://www.youngfoundation.org/publications/social-innovationwhat-it-is-why-it-matters-how-it-can-be-accelerated/

Murray, C., \& Mulgan, G. (2010). The open book of innovation. The Young Foundation.

Nicholls, A., Simon, J., Gabriel, M., \& Whelan, C. (Eds.). (2015). New frontiers in social innovation research. Palgrave Macmillan.

Reffstrup, T., \& Kærn Christiansen, S. (2017). Nordic Entrepreneurship Islands: Status and Potential - Mapping and Forecasting Entrepreneurship Education on Seven Selected Nordic Islands. https://eng.ffe-ye.dk/media/785770/nordic-entrepreneurship-islands-status-and-potential.pdf

Östling, J. (2018). Humboldt and the modern German university: An intellectual history. Lund University Press.

Ranga, M., \& Etzkowitz, H. (2013). Triple helix systems: An analytical framework for innovation policy and practice in the knowledge society. Industry and Higher Education, 27(3), 237-62.

Rayna, T., \& Striukova, L. (2019). Open social innovation dynamics and impact: Exploratory study of a fab lab network. $R \& D$ Management, $49,3$.

Rosenlund, J., Rosell, E., \& Hogland, W. (2017). Overcoming the triple helix boundaries in an environmental research collaboration. Science and Public Policy, 44(2), $153-162$.

SDSN Australia/Pacific. (2017). Getting Started with the SDGs in Universities: A Guide for Universities, Higher Education Institutions, and the Academic Sector. http://ap-unsdsn.org/wp-content/uploads/University-SDG-Guide_web.pdf

Sutherland, J. (2014). SCRUM: The art of doing twice the work in half the time. Random House.

Trencher, Gregory, et al. "Beyond the third mission: Exploring the emerging university function of co-creation for sustainability." Science and Public Policy 41.2 (2014): 151-179. 
Trencher, G., Yarime, M., McCormick, K., Doll, C. N. H., \& Kraines, S. (2013). Beyond the third mission: Exploring the emerging university function of co-creation for sustainability. Science and Public Policy, 41, 151-197.

Tushman, M. (1977). Special boundary roles in the innovation process. Administrative Science Quarterly, 22(4), 587-605.

Vanhaverbeke, W., \& Chesbrough, H. W. (2014). A classification of open innovation and open business models. In H. W. Chesbrough, W. Vanhaverbeke, \& J. West (Eds.), New frontiers in open innovation, p. 50-68. Oxford University Press.

Vanhaverbeke, W., Chesbrough, H. W., \& West, J. (2014). Surfing the new wave of open innovation research. In H. W. Chesbrough, W. Vanhaverbeke, \& J. West (Eds.), New frontiers in open innovation, p. 281-294. Oxford University Press.

Wittrock, B. (1993). The modern university: The three transformations. In S. Rothblatt \& B. Wittrock (Eds.), The European and American university since 1800: Historical and sociological essays, p. 303-362. CUP.

Williams, P. (2002). The competent boundary spanner. Public Administration, 80(1), 103-24.

Wright, T. S. A. (2002). Definitions and frameworks for environmental sustainability in higher education. Higher Education Policy, 15, 105-20.

Zomer, A., \& Benneworth, P. (2011). The rise of the University's third mission. In J. Enders, H. F. de Boer, \& D. F. Westerheijden (Eds.), Reform of higher education in Europe, p. 81-101. Sense Publishers. 